\title{
Benjoin : Jawi, al Bohor, Lebxur, Elluban (ar.)
}

\section{Gast}

\section{OpenEdition}

Journals

Édition électronique

URL : http://journals.openedition.org/encyclopedieberbere/1716

DOI : 10.4000/encyclopedieberbere.1716

ISSN : 2262-7197

\section{Éditeur}

Peeters Publishers

\section{Édition imprimée}

Date de publication : 1 décembre 1991

Pagination : 1472-1473

ISBN : 2-85744-549-0

ISSN : 1015-7344

\section{Référence électronique}

M. Gast, « Benjoin : Jawi, al Bohor, Lebxur, Elluban (ar.) », Encyclopédie berbère [En ligne], 10 | 1991, document B65, mis en ligne le 01 mars 2013, consulté le 25 septembre 2020. URL : http:// journals.openedition.org/encyclopedieberbere/1716; DOI : https://doi.org/10.4000/ encyclopedieberbere.1716

Ce document a été généré automatiquement le 25 septembre 2020.

() Tous droits réservés 


\title{
Benjoin : Jawi, al Bohor, Lebxur, Elluban (ar.)
}

\author{
M. Gast
}

1 Le benjoin est un suc résineux aromatique obtenu par incision d'un arbre des Indes orientales: le Styrax Benzoin Dryander, pour le benjoin de Sumatra qui est le plus employé. Cultivé à Sumatra, à Java, à Bornéo et sur les côtes malaises, le styrax fournit un suc blanchâtre, compact, qui durcit à l'air. Plus l'arbre vieillit, plus son suc s'assombrit en une masse vitreuse jaune et brune, ayant l'apparence d'un nougat. C'est cette dernière qualité commerciale, souvent mélangée à de la terre, de la poudre de bois et autres éléments étrangers que l'on trouve le plus souvent en Afrique du Nord. Le benjoin de Pénang (storax smelling Benjamin des Anglais), mélange de larmes blanches et d'une gangue résineuse, cristalline grise, y semble rare ou inconnu, ainsi que le benjoin de Siam à l'odeur de vanille et qui donne à la mastication une pâte blanche et opaque.

Les Arabes ramenaient le benjoin de Sumatra, « qu'ils confondaient avec Java et lui donnaient le nom d'encens de Java, luban jawi, d'où ses dérivés Banjawi, Benjui, Benjoin et pour les Anglais Benjamin » ( $\mathrm{D}^{\mathrm{r}} \mathrm{R}$. Blondel in La Grande Encyclopédie sous la direction de $M$. Berthelot et al.). Le benjoin n'a guère de nom spécifique dans les dialectes berbères. On emploie ordinairement les termes arabes : jawi, ou encens : lebxur ou encore elluban, qui désigne par ailleurs l'ambre résineux utilisé aussi comme encens.

Issu du commerce oriental et méditerranéen à partir d'une longue chaîne d'échanges et d'intermédiaires, le benjoin a toujours été un produit certes très apprécié, mais assez peu employé par les populations rurales, et encore moins par les nomades, en raison de son prix élevé. C'est la raison pour laquelle l'on trouve souvent des encens de fabrication locale, issu de mélanges de produits aromatiques (et souvent arrosés de parfums) qui se substituent ou s'associent aux emplois du benjoin (voir Gobert, 1962 ; Gast, 1968). Comme toute les substances balsamiques, le benjoin est recommandé contre les affections des voies respiratoires, mais il est aussi employé contre la fièvre, les maux de tête, la tuberculose ou la pleurésie : si la fumée odorante qu'il dégage sur les cassolettes ou les encensoirs chargés de braises ne suffit pas contre ces derniers maux, on le pile pour le faire boire en poudre avec un peu d'eau aux malades (bien qu'il 
ne soit pas soluble dans l'eau). Il est censé aussi avoir un effet bénéfique sur les douleurs rhumatismales et celles au niveau du foie. Mais l'usage du benjoin a surtout un effet psychologique sur les êtres, dans les lieux qu'il embaume. Il est présenté comme favorisant la paix, le recueillement et l'harmonie entre les personnes qui se trouvent dans une même pièce. Il chasse les mauvais génies du mal et de la discorde. Il peut ainsi « désinfecter " un lieu où est passé quelqu'un de malsain physiquement et moralement. Il participe à différentes compositions atténuant l'agressivité des mauvais génies comme la bçiça signalée par J. Bourrilly au Maroc, "mélange d'encens, de térébinthe, de coriandre, d'huile, de semoule et de sucre que l'on jette aux mauvais génies aux endroits où ils vivent» (Bourrilly, 1932, p. 256). L'épouse fidèle qui attend avec amour le retour nocturne de son mari, encensera discrètement sa chambre à coucher. Lors des grandes fêtes sahariennes durant lesquelles on pratique la danse des fusils appelée baroud, il est fréquent qu'une vieille femme embaume les danseurs à l'aide d'un encensoir balancé au rythme des chants. Cette fumée odorante protège les danseurs des accidents éventuels, atténue l'agressivité des porteurs de fusils et attire la bénédiction de Dieu sur la foule.

\section{BIBLIOGRAPHIE}

Desparmet J., Ethnographie traditionnelle de la Mettidja. Le mal magique, Alger/Paris, J. Carbonnel/ Geuthner, 1932, 350 p.

Bourrilly J., Eléments d'ethnographie marocaine, Paris, Librairie coloniale et orientaliste Larose, $1932,262 \mathrm{p}$.

Gast M., « Usage des encens dans le Sahara central », Libyca, XVI, 1968, pp. 171-174.

Gobert E.-G., « Tunis et les parfums », Revue Africaine, t. CVI, 1962, pp. 75-118.

INDEX

Mots-clés : Biographie, Commerce, Ethnographie, Religion 